\title{
Diversity of soil fungal communities of Cerrado and its closely surrounding agriculture fields
}

\author{
Alinne Pereira de Castro $\cdot$ Betania Ferraz Quirino • \\ Georgios Pappas Jr • Adriane Silva Kurokawa • \\ Eduardo Leonardecz Neto • Ricardo Henrique Krüger
}

Received: 27 October 2007 / Revised: 7 April 2008 / Accepted: 14 April 2008 / Published online: 6 May 2008

(C) Springer-Verlag 2008

\begin{abstract}
Cerrado is a savanna-like region that covers a large area of Brazil. Despite its biological importance, the Cerrado has been the focus of few microbial diversity studies. A molecular approach was chosen to characterize the soil fungal communities in four areas of the Cerrado biome: a native Cerrado, a riverbank forest, an area converted to a soybean plantation, and an area converted to pasture. Global diversity of fungal communities in each area was assessed through Ribosomal intergenic spacer analysis which revealed remarkable differences among the areas studied. Sequencing of approximately 200 clones containing $18 \mathrm{~S}$ rDNA sequences from each library was performed and, according to the genetic distance between sequences, these were assigned to operational taxonomic units (OTUs). A total of $75,85,85$, and 70 OTUs were identified for the native Cerrado, riverbank forest, pasture, and soybean plantation, respectively. Analysis of sequences using a similarity cutoff value of $1 \%$ showed that the number of OTUs for the native Cerrado area was reduced by $35 \%$; for the soybean plantation, a reduction by more than $50 \%$ was observed, indicating a reduction in fungal biodiversity associated with anthropogenic activity. This is the first study
\end{abstract}

Communicated by Erko Stackebrandt.

Electronic supplementary material The online version of this article (doi:10.1007/s00203-008-0374-6) contains supplementary material, which is available to authorized users.

A. P. de Castro - B. F. Quirino - G. Pappas Jr · A. S. Kurokawa ·

E. L. Neto $\cdot$ R. H. Krüger $(\square)$

Genomic Sciences and Biotechnology Program,

Universidade Católica de Brasília, SGAN Quadra 916,

Av. W5 Norte, Cep. 70.790-160 Brasília, DF, Brazil

e-mail: kruger@pos.ucb.br demonstrating the anthropogenic impact on Cerrado soil fungal diversity.

Keywords Fungal diversity $18 \mathrm{~S}$ rDNA .

Diversity indices · Anthropogenic modified soils

\section{Introduction}

Savannas are tropical and subtropical formations characterized by an almost continuous grass layer, interrupted only by shrubs and trees in varying proportions, and in which the main growth patterns are closely associated with alternating wet and dry seasons. The Brazilian Cerrado is the main savanna region in the Americas and used to cover about 2 million $\mathrm{km}^{2}$, mainly in the Brazilian central plateau, under a seasonal climate of wet summers and dry winters (Ratter et al. 1997). Cerrado is a savanna-like region that covers a large area of Brazil, roughly equivalent to half the size of the European Union. Despite its biological importance, the Cerrado biome has been the focus of very few studies about its biological diversity.

The productivity of agricultural systems is, in part, dependent upon the functional processes of soil microbial communities (O'Donnell et al. 1994; Doran and Zeiss 2000). However, little information is available about the contribution of fungal microbial diversity in soil ecosystem functioning. In the last two decades, the Cerrado biome has been rapidly converted to pastures and agricultural fields (Marris 2005). The impact of these athropogenic activities on the fungal microbial community has not been studied.

Several studies have found decreased levels of microbial biomass, diversity, and altered community structure due to disturbance mostly caused by pesticides and sludge amendments in agricultural fields (Engelen et al. 1998; Smit et al. 
Table 1 Comparison of selected soil physical-chemical characteristics of the studied areas

a A comparison of all 28 tested parameters appears on supplemental material S1

\begin{tabular}{lcccc}
\hline Parameter $^{\mathrm{a}}$ & Cerrado senso strictu & Pasture & Riverbank forest & Soybean plantation \\
\hline $\mathrm{pH}$ & 4.7 & 6.2 & 4.4 & 6.0 \\
Organic matter $(\mathrm{g} / \mathrm{kg})$ & 160.8 & 223.1 & 133.4 & 210.1 \\
$\mathrm{~N}(\mathrm{mg} / \mathrm{kg})$ & 210 & 280.0 & 210.0 & 280.0 \\
$\mathrm{NH}_{4}-\mathrm{N}(\mathrm{mg} / \mathrm{kg})$ & 140 & 140.0 & 70.0 & 70.0 \\
$\mathrm{NO}_{3}{ }^{-}-\mathrm{N}(\mathrm{mg} / \mathrm{kg})$ & 140 & 140.0 & 210.0 & 210.0 \\
$\mathrm{Zn}(\mathrm{ppm})$ & 1.2 & 28.5 & 3.0 & 12.2 \\
$\mathrm{Silt}(\mathrm{g} / \mathrm{kg})$ & 216 & 649.0 & 593.0 & 628.0 \\
$\mathrm{Clay}(\mathrm{g} / \mathrm{kg})$ & 511.0 & 308.0 & 378.0 & 220.0 \\
Sand $(\mathrm{g} / \mathrm{kg})$ & 273 & 43 & 29 & 152 \\
$\mathrm{P}(\mathrm{ppm})$ & 0.6 & 1.9 & 5.6 & 14.4 \\
$\mathrm{~K}(\mathrm{ppm})$ & 78.2 & 39.1 & 97.8 & 148.6 \\
\hline
\end{tabular}

1999; Josen et al. 2001). On the other hand, despite anthropogenic activities, gross microbial processes and their potential role in maintaining soil quality can remain unaffected most likely due to functional redundancy of soil microorganisms (Ohtonen et al. 1997; Wertz et al. 2006, 2007). Also, natural or human-induced perturbations may influence the level of soil microbial activities without causing compositional shifts in soil communities' structure (Giller et al. 1997; Hunt et al. 2004). Another example of anthropogenic environment modification is the introduction of transgenic plants. At least for transgenic soybean varieties, some mycorrhizal and rhizobial colonization shifts have been observed but were not correlated with transgenic soybean plants (Powell et al. 2007).

It has been estimated that 1.5 million fungal species are present in natural ecosystems, but only 5-10\% have been described formally (Hawksworth 1991; Hawksworth and Rossman 1997). The aim of the present study was to evaluate the impact of intensive soil management practices and cultivation on the fungal community structure of Cerrado soils. There are several different methods to study soil microbial diversity each with its strengths and weaknesses (Kirk et al. 2004). To characterize and compare the soil fungal communities present in four different fields of the Cerrado biome (a native Cerrado sensu stricto, a riverbank forest, a former sensu stricto area converted to a soybean plantation, and a former sensu stricto area converted to pasture) two molecular approaches were chosen. One was rRNA intergenic spacer analysis (RISA), which is a powerful method that yields a genetic fingerprint at the community level, providing a rapid and global estimate of the fungal community composition. The other molecular approach used was PCR amplification of variable regions of $18 \mathrm{~S}$ fungal ribosomal DNA using specific primers that hybridize to conserved regions that flank the polymorphic region. The PCR products obtained were cloned to construct libraries, one for each area studied, and clones from these libraries were sequenced and identified.

\section{Methods}

Description of sites and soil characteristics

Soil samples were collected in a field of Cerrado sensu stricto $\left(16^{\circ} 32^{\prime} 29.8^{\prime \prime} \mathrm{S}, 4^{\circ} 34^{\prime} 9.6^{\prime \prime} \mathrm{W}\right)$, a former Cerrado sensu stricto field converted to a pasture $\left(16^{\circ} 34^{\prime} 18.1^{\prime \prime} \mathrm{S}\right.$, $\left.47^{\circ} 35^{\prime} 4.1^{\prime \prime} \mathrm{W}\right), \quad$ a riverbank forest $\left(16^{\circ} 33^{\prime} 19.7^{\prime \prime} \mathrm{S}\right.$, $\left.47^{\circ} 34^{\prime} 3.3^{\prime \prime} \mathrm{W}\right)$, and a former sensu stricto field converted to a soybean plantation $\left(16^{\circ} 33^{\prime} 44.9^{\prime \prime} \mathrm{S}, 47^{\circ} 34^{\prime} 21.2^{\prime \prime} \mathrm{W}\right)$ in the dry season of 2005 in the month of January in the municipal district of Cristalina, state of Goiás, Brazil. These fields are located in the same general area. The field site that was a former Cerrado sensu stricto area and is now a pasture area has been subjected to intensive pasture for the past 24 years. The other Cerrado sensu stricto area that was converted to agricultural purposes has been cultivated with soybean for the past 21 years. To obtain a representative sample of the four areas of interest, five different sites within each area were sampled to generate a mixed sample. All soil samples were collected from the upper layer $(0$ $10 \mathrm{~cm}$ ) and were sieved through a $2-\mathrm{mm}$ mesh sieve to remove large particles and plant material. Soil samples were kept on ice until arrival in the laboratory where they were stored at $-20^{\circ} \mathrm{C}$. Soil physical-chemical characteristics were determined by standard techniques (Table 1) and used to generate a principal component analysis (PCA) plot with the software SAS ${ }^{\circledR}$ (Statistical Analysis System), SAS Institute, Inc. (2005). Release 8.02, Cary, NC, USA (Fig. 1).

Soil DNA extraction, purification, and PCR amplification

Direct soil DNA extraction from $5 \mathrm{~g}$ of soil was performed as described by (Yeates et al. 1998) with modifications (Quirino et al. 2007). The DNA was purified using the UltraClean TM 15 Kit (MOBIO Laboratories, Inc.) according to the manufacturer's instructions. PCR amplification of 


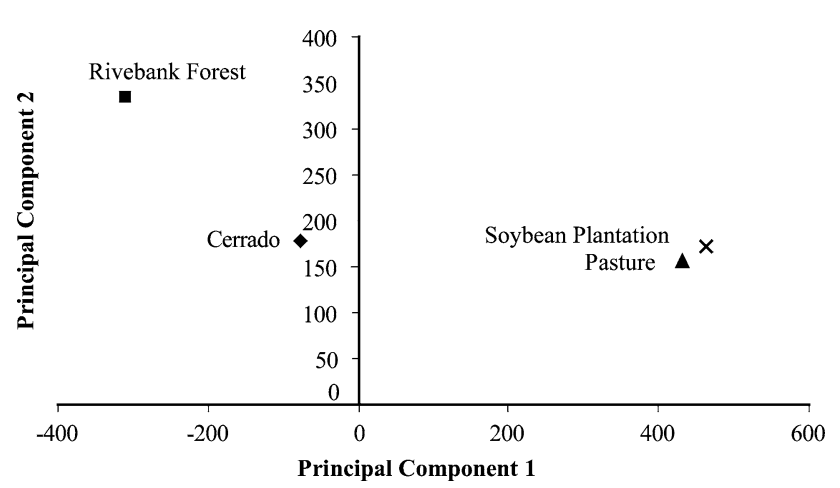

Fig. 1 PCA of 28 multiple physical-chemical soil parameters of the four areas studied using SAS ${ }^{\circledR}$ software

18S rDNA was performed using fungal-specific primers EF4f (5'GGA AGG G [G/A] T GTA TTT ATT AG 3') and Fung5 (5'GTA AAA GTC GTC GTT CCC $3^{\prime}$ ) as designed by Smit et al. (1999) using a Thermocycler (Perkin-Elmer, Waltham, Massachusetts, USA). Each $50 \mu$ PCR reaction contained $10 \mathrm{ng}$ of metagenomic soil DNA, $20 \mu \mathrm{M}$ of each primer, $2.5 \mathrm{mM}$ dNTPs (Promega, Madison, WI, USA), $1 \times$ Taq reaction buffer and $5 \mathrm{U}$ Taq DNA polymerase (GIBCO-BRL, New York, USA). The cycling protocol started by heating reactions to $94^{\circ} \mathrm{C}$ for $3 \mathrm{~min}$, followed by 25 cycles of $1 \mathrm{~min}$ at $94^{\circ} \mathrm{C}, 1: 30 \mathrm{~min}$ at $51^{\circ} \mathrm{C}$, and $1: 30 \mathrm{~min}$ at $72^{\circ} \mathrm{C}$, ending with a final step at $72^{\circ} \mathrm{C}$ for $15 \mathrm{~min}$.

\section{Cloning of PCR products}

PCR products were purified by $0.8 \%$ agarose gel electrophoresis. The band of interest was excised and extracted using UltraClean TM 15 Kit (MOBIO Laboratories Inc.) according to the manufacturer's instructions. Cloning experiments were conducted following the pGEM-T Easy Vector System I manufacturer's instructions (Promega, Madison, WI, USA). Briefly, $10 \mathrm{ng}$ of PCR amplified DNA was ligated to the pGEM-T Easy Vector and transformed into competent cells (Escherichia coli $\mathrm{DH} 5 \alpha$ ) by electroporation. Serial dilutions were plated on LB (Luria-Bertani) plates with ampicillin/IPTG/X-Gal and incubated overnight at $37^{\circ} \mathrm{C}$. White colonies on each plate were selected and cultured overnight at $37^{\circ} \mathrm{C}$ in LB broth with agitation. The recombinant plasmid DNA was then extracted using QIAprep Spin Miniprep Kit (QIAGEN, Australia) according to the manufacturer's instructions.

\section{Sequencing of clones}

Sequencing reactions of the selected clones were performed using an automated DNA sequencer ABI PRISM 377 (Applied Biosystems). Plasmid DNA preparations were performed on microtiter plates according to the standard protocols (Maniatis et al. 1982). Plasmid DNA was used as a template for PCR cycle sequencing (Perkin-Elmer) using a T7 primer (Invitrogen) and the DYEnamic ET Terminator Cycle Sequencing Kit (Amersham Biosciences) was used according to the manufacturer's instructions. To confirm the identity of nucleotides, each clone was sequenced two times.

Phylogenetic analysis

All sequences were processed into high-quality sequences using a previously reported sequence program (Pappas et al. 2005). After removal of chimeric artifacts using the Bellerophon program (Huber et al. 2004), sequences were compared to the non-redundant database of sequences deposited at the National Center for Biotecnology using Blastn (Altschul et al. 1990). Sequences were aligned using the program MUSCLE (Edgar 2004) and then the alignment was manually proofread and corrected when necessary using Bio Edit (URL: http://www.mbio.ncsu.edu/ BioEdit/). Aligned sequences were clustered into operational taxonomic units (OTUs) using the DOTUR (distance-based OTU and richness) program (Schloss and Handelsman 2005). Jukes-Cantor evolutionary distances were calculated using DNADIST of the PHYLIP 3.63 package (J. Felsenstein; http://evolution. genetics.Washington.edu/phylip.htlm) and $\int$-LIBSHUFF (Schloss et al. 2004) was used to estimate the significance of differences between the four microbial libraries.

Ribossomal RNA intergenic spacer analysis (RISA)

The polymorphism length of the ITS1-5.8 S-ITS2 region was exploited to characterize the fungal community. The primers used to amplify this region, 3126T (5'ATAT GCTTAAGTTCAGCGGGGT3') and 2234C (5'GTTTCC GTAGGTGAAACCTGC3') represent consensus sequences found at the $5^{\prime}$ end and $3^{\prime}$ end, respectively, of the $18 \mathrm{~S}$ genes in various eukaryotic organisms (Sequerra et al. 1997). Each $20 \mu \mathrm{l}$ of PCR reaction mixture contained $2 \mathrm{mM}$ dNTPs (Promega, Madison, WI, USA), 2.5 U Taq polymerase (GIBCO-BRL), $20 \mu \mathrm{M}$ of each primer, $1 \times$ Taq reaction buffer, and 10 ng DNA template. The cycling scheme was a step at $94^{\circ} \mathrm{C}$ for $3 \mathrm{~min}$, followed by 25 cycles of $94^{\circ} \mathrm{C}$ for $1 \mathrm{~min}, 55^{\circ} \mathrm{C}$ for $1: 30 \mathrm{~min}$, and $72^{\circ} \mathrm{C}$ for $1: 30 \mathrm{~min}$, and a final step at $72^{\circ} \mathrm{C}$ for $15 \mathrm{~min}$.

Amplified ribossomal DNA restriction analysis

Enzymatic restriction of amplified ribosomal DNA was performed as described for RISA for $16 \mathrm{~h}$ at $37^{\circ} \mathrm{C}$ in $10 \mu \mathrm{l}$ volume of $1 \mathrm{X}$ commercially supplied incubation buffer containing $5 \mathrm{U}$ of restriction enzyme $A l u \mathrm{I}\left(\mathrm{AG}^{\prime} \mathrm{CT}\right)$ (Promega, Madison, WI, USA). The fragments of DNA 
obtained were separated on an $8 \%$ polyacrylamide gel, run at $1,500 \mathrm{~V}$ for $6 \mathrm{~h}$, and visualized by silver staining.

\section{Accession numbers}

All 18S rDNA sequences described in this study are available at Genbank. Sequences obtained from Cerrado sensu stricto, Cerrado converted to pasture, riverbank forest, and soybean plantation soils were assigned the consecutive accession numbers EF673298 to EF673686.

\section{Results}

\section{Soil analysis}

For the soil samples collected in the four areas studied 28 different soil physical-chemical characteristics were determined by standard methods. The main parameters are shown in Table 1. All 28 parameters available were used in a PCA using the SAS $^{\circledR}$ software that generated a scatterplot graph showing the relationship between the four areas studied. This analysis showed that the most similar soils were those from the pasture and soybean plantation areas. In contrast, the soil from the riverbank forest soil and native Cerrado area were the ones that differed between themselves and from the other sites (Fig. 1).

Various methods to assess fungal communities in soil have been developed, which have great potential to contribute to a better understanding of the ecological role of fungi in soil habitats. Diversity described as the total number and abundance of fungal species may not be determinable in soils due to limitations in taxonomic definitions and methods; thus, composition of fungal communities may generally be described by fungal community structures (Anderson and Cairney 2004; Kirk et al. 2004; Schwarzenbach et al. 2007).

\section{RISA community profile}

RISA produces hundreds of discrete bands ranging in size from 100 to $1,400 \mathrm{bp}$. RISA may be used for rapid high throughput screening of soil community structures when detection of differences or change is more important than the phylogenetic identification of the organisms affected. The different banding patterns among the fields studied was reproducibly observed and suggests that each soil contains a unique microbial population. These differences in microbial communities are possibly the result of differences in the properties of the soil from each area studied (Reiners et al. 1994). The largest number of DNA bands was obtained from the riverbank forest soil (Fig. 2a). This result is similar to that obtained by Franklin et al. (2006) and may be related to high decomposition activity in this area. Genetic fingerprinting was obtained by RISA of the ITS15.8 S-ITS2 region amplified fragments from the DNA extracted from soil by the direct extraction method (Quirino et al. 2007). RISA patterns showed a few strong dominating bands and a great number of faint poorly separated bands (Fig. 2a). Due to the difficulty in analyzing such a complex profile, an amplified $18 \mathrm{~S}$ ribosomal DNA restriction analysis (ARDRA) with the endonuclease AluI was attempted (Fig. 2b). Profiles of replicates were reproducible and this facilitated image analysis of RISA banding patterns using the software Bionumerics-Cluster (version 3.5; Applied Maths, Kortrijk, Belgium) with Dice similarity coefficient directly applied to the array of densitometry values forming the fingerprint. The UPGMA algorithm was used to cluster the data. The software calculated the percentage of similarity between lanes, taking into account the migration distance and the relative intensity of all bands. The clusters indicated that the most different fungal community studied is the one present in the riverbank soil. In contrast, the fungal communities present in the former sensu stricto area converted to a pasture and Cerrado sensu stricto area are the most similar (Fig. 2a, b).

\section{S rDNA Libraries construction}

The DNA extracted from the soil community was approximately $12,000 \mathrm{bp}$ in size (data not shown). The extracted DNA was successfully amplified with fungal-specific primers EF4f and Fung5r giving products of $550 \mathrm{bp}$. These fragments were eluted from the gel and cloned to generate four 18S rDNA libraries: one from Cerrado sensu stricto, one
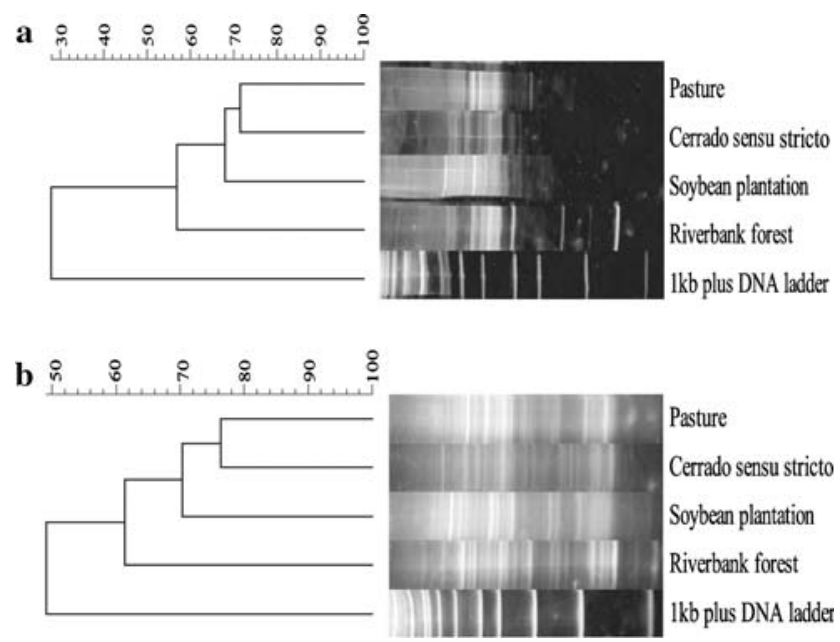

Fig. 2 a, Analysis of fungal communities with RISA without digestion. $\mathbf{b}$, Analysis of fungal communities with ARDRA using AluI. This dendrogram was constructed using the UPGMA algorithm and the DICE similarity coefficient. The DNA weight marker was used as the out-group 
from the riverbank forest, one from the soybean plantation, and one from the pasture.

One hundred and ninety-two clones from each of the four $18 \mathrm{~S}$ rDNA libraries were randomly selected for sequencing. After removal of chimeric sequences and those of low quality, a total of 85, 103, 96, and 105 clones of native Cerrado, riverbank forest, pasture, and soybean plantation, respectively, remained to be further analyzed. All sequences obtained were of fungal origin, demonstrating the specificity of the pair of primers used in hybridizing to the conserved region of fungal $18 \mathrm{~S}$ rDNA. Analysis of sequences derived from the four libraries showed that representatives of the phylum Ascomycetes were clearly dominant in all the communities studied (Fig. 3). This dominance was most prominent in the pasture and soybean plantation areas where Ascomycetes accounted for 90.5 and $88 \%$, respectively. Basidiomycetes were also identified in all the areas studied, however, they were more abundant in the Cerrado sensu stricto $(27.4 \%)$ and riverbank forest (36\%) compared to pasture $(4.1 \%)$ and soybean plantation $(2.3 \%)$ areas. "Uncultured" soil fungi were predominant in the riverbank forest area corresponding to $11.4 \%$ of sequences and in Cerrado sensu stricto corresponding to $8.2 \%$ of the sequences obtained. These sequences showed similarity in the range of $95-99 \%$ to sequences deposited in GenBank of unidentified fungi. Sequences of the phylum Chytridiomycetes were only observed in the soybean plantation area $(8.2 \%)$.

\section{Computational analysis}

The program DOTUR was used to calculate diversity indices, richness estimators and to construct randomized rarefaction curves. The probability of drawing a representative from an OTU is the number of times the OTU observed divided by the total number of sequences in the library (Schloss and Handelsman 2005). A total of 75, 85, 85, and 70 OTUs (Fig. 4) were identified for the Cerrado sensu stricto, riverbank forest, pasture, and soybean plantation, respectively. Rarefaction curves using an evolutionary distance of 0.01 or 0.03 (which equal to one and three mismatches in the DNA sequence per $100 \mathrm{bp}$, respectively) showed that the area that presented a greater decrease in diversity was the soybean plantation with reduction of almost 50\% in the OTUs identified when compared to the "unique" sequences curve. In contrast, in a similar analysis, the Cerrado sensu stricto area presented a decrease of only $35 \%$ in the OTUs identified.

In order to investigate this behavior in more detail, the species diversification rate for each sample was analyzed by "lineage-through-time" plots, which describe the number of OTUs according to the evolutionary distance (Schloss and Handelsman 2005). Such plots were also obtained from DOTUR and are shown in Fig. 5. These graphs are based on a nonrandomized collector's curve and are an estimate of the expected richness (rather than observed richness). Species richness was estimated by using the Chao1, a nonparametric species richness estimator adapted from the mark-release-recapture (MRR) statistics for estimating the size of animal populations that is suitable for use with microbial communities (Hughes et al. 2001). This analysis shows that the expected richness for the soybean plantation is lower than that for pasture and Cerrado sensu stricto. The riverbank fungal community is expected to be the richest.

To evaluate if the differences observed in the composition of the fungal communities are statistically significant, the $\int$-Libshuff program (Schloss et al. 2004) with 10,000 randomizations was used. These analyses illustrate the
Fig. 3 Fungal diversity in a Cerrado sensu stricto, b riverbank forest, $\mathbf{c}$ pasture, and $\mathbf{d}$ soybean plantation soils $18 \mathrm{~S}$ rDNA gene library
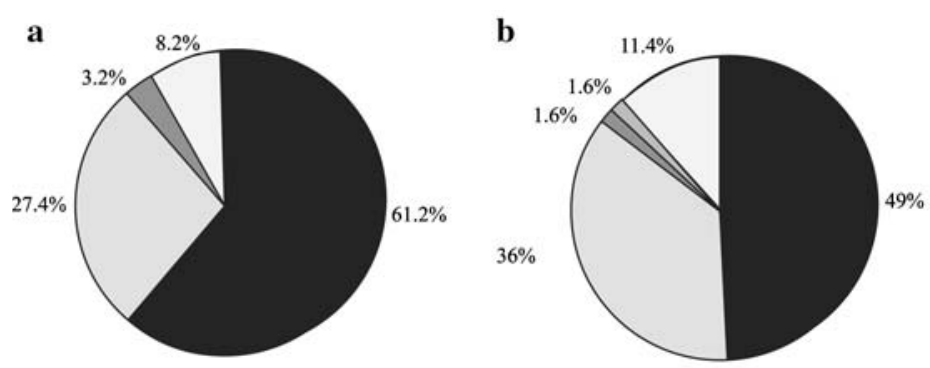

Ascomycetes

$\square$ Basideomycetes

Zygomycetes

Glomeromycetes

Chytridiomycetes

Uncultered soil fungus

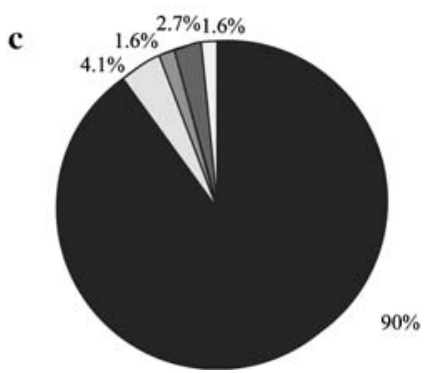

d

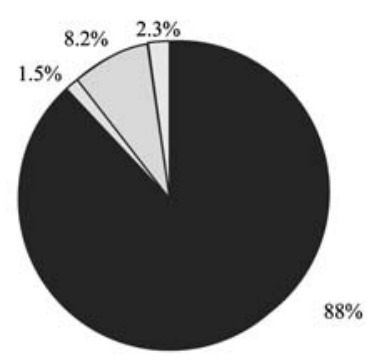


Fig. 4 Rarefaction curves from DOTUR analysis of sequences from a Cerrado sensu stricto, b riverbank forest, $\mathbf{c}$ pasture, and d soybean plantation soils $18 \mathrm{~S}$ rDNA gene library for various distance levels. Error bars representing a $95 \%$ confidence interval were omitted for clarity
Fig. 5 Lineage-through time plot from DOTUR analysis using the furthest neighbor assignment algorithm. The average number of predicted OTUs for each of the four 18S rRNA gene libraries according to the evolutionary distance is shown for a Cerrado sensu stricto, b riverbank forest, $\mathbf{c}$ pasture, and $\mathbf{d}$ soybean plantation soils. The number of OTUs refers to the average in a 1,000 sample bootstrap simulation and error bars representing a $95 \%$ confidence interval are shown
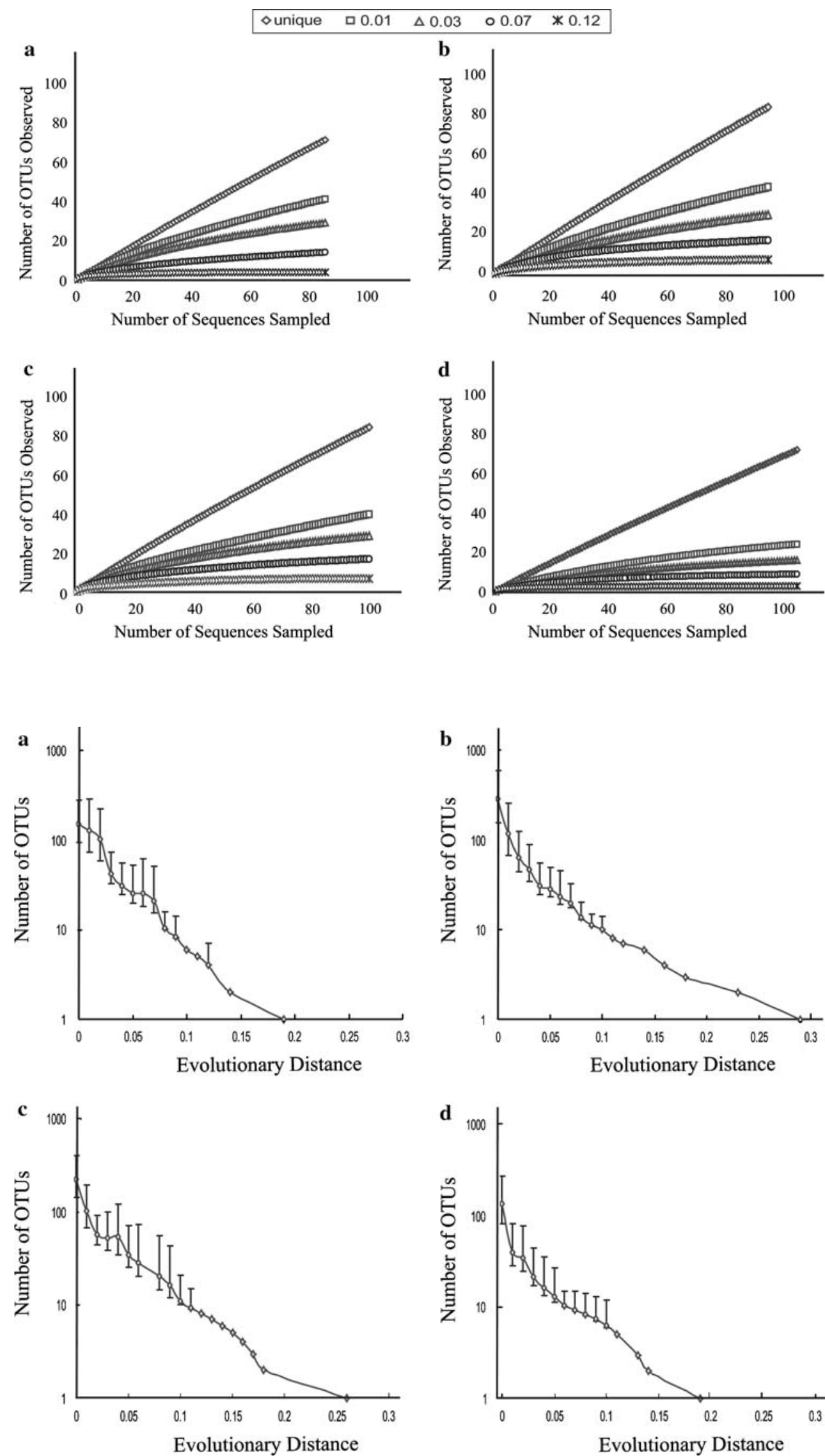
power of $\int$-Libshuff to detect differences between communities, providing the basis for ecological inferences about the association of soil microbial community composition. The significant $P$ values obtained $(P<0.0001)$ show that none of the libraries is a subset of the others (Singleton et al. 2001; Schloss and Handelsman 2004 and Supplemental Material S6).

\section{Discussion}

The Cerrado biome has two distinct seasons, dry and rainy. Another important factor is that our soil samples were acquired in the peak of the dry season. This observation can account for the expected richness similarity in the Cerrado sensu stricto, and pasture where water availability is limited. Nevertheless, our data suggest that continuous human interference, especially frequent irrigation, associated with Cerrado conversion to soybean plantation leads to a distinct fungal community richness.

The soil physical-chemical analysis clearly showed the impact of soil management in the native soil composition. To quickly access a possible influence of these modifications in the fungal soil communities we performed RISA to verify global changes in these communities structure. This result immediately suggests that, indeed, these soil physical-chemical perturbations may be one of the factors playing a role in the fungal community's richness (i.e.; the number of species in the community which along with the abundance of each species in the community will determine the biodiversity).

The extracted DNA was successfully amplified with fungal-specific primers EF4f and Fung5r and yielded products of $550 \mathrm{bp}$, which was consistent with the results obtained by Smit et al. (1999). The fungal-specific primers used in this study were selected to provide optimal specificity for a wide range of fungi, however, other authors have shown that this pair of primers is also able to amplify $18 \mathrm{~S}$ rDNA sequences of invertebrates (Anderson et al. 2003). Nevertheless, only fungal amplicons were found in our libraries. Although primer bias could be a limitation, it remains uncertain that this bias can impact overall fungal community structure predictions (Anderson and Cairney 2004). Analysis of sequences derived from all libraries showed that the phylum Ascomycetes is clearly the dominant phylum. This result can be attributed to the primers Ef4-fung5 preference to amplify this phylum, as previously observed by Smit et al. (1999). Although these results are contrasting with the results of Hunt (2004) where they found more Basideomycetes than Ascomycetes sequences, this result is not unexpected. Despite the possible primer bias, this result revealed that Ascomycetes could be the most important phylum of fungi in these soils in accordance with the culture-based analysis of fungi that has identified mostly Ascomycetes (Vandenkoornhuyse et al. 2002). The most striking feature from the sequences analysis is the shift towards Ascomycetes in the soils modified by human activity when compared with the native soil. Ascomycetes include an ample variety of taxa that are known saprophytes as well as numerous endophytic fungi associated with plant roots (Jumppoonem and Trappe 1998). A similar trend was observed in a bacterial community analysis where the pasture soil was dominated by a specific group of bacteria (Actinomyces) reducing the richness observed in the native Cerrado soil (Quirino et al. 2007). Although the phylum Ascomycetes became the most dominant group in the anthropogenic modified areas, we also observed the phylum Chytridiomycetes only in the former sensu stricto area converted to a soybean plantation. The phylum Chytridiomycetes is a group of fungi distinguished by having zoospores (motile cells) with a single, posterior, whiplash structure (flagellum). Most species are microscopic in size and are found in freshwater or wet soils. Most are parasites of algae and animals or live on organic debris. In our study the detection of the phylum Chytridiomycetes solely in the soybean plantation soil can be attributed to several factors such as changes in soil parameters, monoculture vegetation coverage due to intensification of agriculture, or a beneficial interaction with the now dominant Ascomycetes (Table 1, Fig. 1, and Tilman 1999). On the other hand, all the areas had 18S rDNA sequences from fungi not yet identified indicating the absence of similar sequences deposited in the database or possibly that these organisms have not been previously isolated. This group of "not identified" fungi is more prominent in the native soils of Cerrado sensu stricto $(8.2 \%)$ and riverbank forest $(11.4 \%)$ when compared with the anthropogenic modified soils present in the soybean plantation (1.5\%) and pasture areas (2.3\%). A similar result was also described by (Jizheng et al. 2005). These analyses show that the distributions of fungi by phylum in the two native areas are similar and the same is observed for the two anthropogenic modified areas. However, when the native and converted areas are compared there is a clear contrast in phyla distribution. Previous studies have demonstrated that the conversion of the native areas can modify the properties of the soil, as the conversion to pasture can cause an increase in $\mathrm{pH}$ and $\mathrm{NH}_{4}{ }^{+}$, as well as a reduction in $\mathrm{NO}_{3}{ }^{-}$(Reiners et al. 1994), Table 1. Since the Ascomycetes are intimately associated with plant roots, not only soil parameters, but the extensive replacement of the plant coverage in the impacted areas may also be an important factor dictating the fungal community structure.

Although results based on simple DNA bands profile analyses (RISA or ARDRA) in polyacrylamide gels or cloning and sequencing of rDNA can describe the composition of the microbial community in soil, statistical methods 
are necessary to quantify and to compare microbial communities. One difficulty is to determine how many clones should be sequenced to represent the diversity of a single soil sample. Another important caveat is the heterogeneity of fungi distribution in soil, where their growth usually is observed in patches rather than a homogeneous distribution (Girvan et al. 2004; Schwarzenbach et al. 2007; Wolfe et al. 2007). We have tried to minimize this possible bias simply by collecting samples from different spots in each area studied and mixing them to obtain a composite sample. The production of abundance curves of species and collector's curves have shown that for agricultural soils the number of $18 \mathrm{~S}$ rDNA clones required to study diversity is substantially less than the number required for studies based on 16S rDNA (Anderson et al. 2003). However, the total number of microbes may be just too large to be counted exhaustively to yield a reliable absolute number (Hughes et al. 2001) and perhaps with the available molecular biology tools it is more useful to compare relative diversities among different sites.

The program DOTUR was used to calculate the diversity indices, richness estimators and to construct randomized rarefaction curves. A rarefaction curve is a statistical method commonly used to compare the observed richness among sites that have been unequally sampled. The area presenting the greatest species richness was the riverbank forest, which possibly is related to the greater number of micro-environments suitable for fungal species development, including the continuous availability of water. The area presenting the greatest reduction in richness was the Cerrado sensu stricto field converted to a soybean plantation. On the basis of the rarefaction curves, the field with the greatest reduction in number of species is under human use for soybean plantation and pasture (Fig. 4). The basis of modern monoculture agricultural methods involves drastic native vegetation removal, irrigation and mechanized harvest. This intense agricultural management leads to loss of soil fertility and consequently the micro-environments associated with the soil should drastically change. Furthermore, excess use of chemical products to control weeds and pathogens also may play a role in reducing the microbial richness. The same process of deforestation and substitution of the native vegetation with a species of grass (Brachiaria brizantha) was used for the pasture area. Although the pasture could be considered a monoculture field, anthropogenic intervention is much more limited when compared to a commercial plantation of soybean. Intensification of soil use for monocultures leads to great soil degradation, ecological unbalance, and chemical contamination of the environment. Other studies have also shown that changes in physical-chemical properties of soil can affect soil microbial composition (Crecchio et al. 2004).
Analysis of the phylogenetic trees indicates that the undisturbed soils have a higher number of fungal species (i.e. higher number of clades) when compared with the anthropogenic modified areas corroborating our OTUs rarefaction curves analysis. The closest relatives presented on these trees also show the most prevalent species in each of the four studied areas (Supplemental Material S2 to S5). We retrieved from our Cerrado sensu stricto soil 18S rDNA library (Supplemental Material S2) many DNA sequences for which the closest relative is the fungal genus Elsione sp., although not as often as found in the pasture soil (below). Once again, this result shows the similarities between the Cerrado and pasture soils. Tricholoma myomyces is also one of the commonly found sequences on our Cerrado sensu stricto library. The genus Tricholoma contains a large number of fairly fleshy white-spored gilled mushrooms which are found worldwide generally growing in woodlands. These are ectomycorrhizal fungi, existing in a symbiotic relationship with various species of coniferous or broad-leaved trees promoting the germination of seedlings (Massicotte et al. 2007).

Psilocybe stunzii and Kraurogymnocarpa trochleospora are the most commonly found sequences on the forest soil and are typical of this type of soil (Supplemental Material S3). P. stunzii belongs to the genus Psilocybe. It is a hallucinogenic fungus, frequently found in regions with high rainfall, in the grass and moss (Saldarriaga et al. 1994). There are estimated to be as many as eight Psilocybe hallucinogenic species containing psychoactive alkaloids, such as psilocybin and psilocin. K. trochleospora (Pseudoarachniotus trochleosporu) is usually isolated from soils with high organic content and have high cellulolytic activity (Udagawa and Uchiyama 2001).

Although also found in the Cerrado soil, one of the most frequently $18 \mathrm{~S}$ rDNA sequences found associated with the pasture soil belongs to the order Myriangiales within the class Dothideomycetes (Supplemental Material S4). This order is represented by several plant pathogens and includes the genus Elsione sp. Elsinoe species are a common cane and foliage disease of brambles (Swart et al. 2001). Disease losses can occur from defoliation, general stunting and a decrease in cane vigor, reduction in fruit yield and quality, and cane death.

The soil from the soybean plantation area is dominated by the fungi order of Hypocreales within the class Sordariomycetes (Supplemental Material S5). Hypocreales are perithecial Ascomycetes recognized by their fleshy and usually brightly colored perithecia. Most of them have a phialidic conidial state. Several are important plant parasites, including species of Nectria and their anamorphs of Fusarium, Verticillium, and Gliocladium. They cause wilts, cankers, root rots, and a variety of plant problems. Reports point to an abundance of $G$. roseum (the anamorph of Nectria 
ochroleuca) within senescent and dead roots and foliage of a wide variety of plants and in plants weakened by stress factors such as herbicides and disease (Dashwood et al. 1993). Intriguingly, $N$. ochroleuca is known to colonize, without symptom production, apparently healthy roots, stems, pods, and seeds of soybean (Schiller and Sinclair 1984; Sutton et al. 1997). In these cases, the fungus apparently colonized the host as a nonpathogenic parasite, and in soybean at least, the association is systemic. There are evidences that Nectria species are pathogenic to apple fruits, potato tubers, conifer seedlings and several tree species (Theron and Holtz 1991; Arnold et al. 2003).

The lineage-through-time plot (Fig. 5) shows that the expected richness of species for the soybean plantation soil is the lowest. The higher expected richness of species for Cerrado sensu stricto and riverbank soil may be due to the diversity in the vegetation coverage and higher organic matter decomposition in the riverbank forest. The intriguing result was that the expected richness for pasture was lower but similar to the non-cultivated soils. The area occupied by pasture analyzed in this study was covered by the native Cerrado vegetation until 1983 and this covering was removed by deforestation and burning. Since then, the soil received annual rounds of fertilization and $B$. brizantha replaced the original vegetation. The presence of cattle in high numbers generating manure keeps the soil fertilized and this could account for the expected richness being similar to that of the riverbank forest and Cerrado sensu stricto.

The analyses with the program $\int$-LIBSHUFF indicated that all libraries had $P$ values of $<0.001$ (Supplemental Material S6), suggesting that these 18S rDNA gene libraries contain different taxonomical ancestries, or that the samples from the four libraries analyzed are significantly different (Singleton et al. 2001; Schloss et al. 2004).

Finally, assessment of the genetic diversity of the fungal community is central to understanding the potential effects of environmental perturbation. Our study shows that analyses of the 18S rRNA gene appear to be a more reliable and useful indicator than RISA profiles to describe the effects within the structure of fungal communities under different soil management practices. However, both methods have limitations with respect to describing quantitative and qualitative changes in the composition of soil fungal community, and in determining which microorganisms are mainly affected by the soil management under investigation. Therefore, other research groups have been using PCR/RFLP and T-RFLP analyses to build objective criteria to assess representativity of soil fungal community profiles (Schwarzenbach et al. 2007). We are in the process of applying these techniques in combination with $18 \mathrm{~S}$ rDNA clone libraries to further advance our Cerrado's soil fungal community studies.
The knowledge of the extension of the phylogenetic diversity can indicate how many functional groups had not been identified yet. Thus, the molecular analysis of the fungal communities of four types of soil (Cerrado sensu stricto, a former sensu stricto field converted to a pasture, riverbank forest, and former sensu stricto field converted to a soybean plantation), suggests that the implanted methodology is capable of detecting, at least in part, the biodiversity of the fungal community in Cerrado soil. Through this methodology we recognized in our samples four major divisions in kingdom Fungi (the Chytridiomycetes, Zigomycetes, Ascomycetes and Basidiomycetes), showing that the microbial diversity of the soil Cerrado biome is considerable, despite the sequencing of a limited number of clones. The number of unknown fungi sequences indicates that the fungal diversity from the soil of this biome is far from being completely described. This ample variability can be influenced by a wide number of environmental factors such as temperature, $\mathrm{pH}$, salinity, availability of water and nutrients, presence of power plants and vegetation coverage. All of these factors that differ among our four soil samples must have influenced the microbial diversity.

As demonstrated for arbuscular mycorrhizal fungi in an experimental mycorrhizal plant system, plant productivity is higher where fungal richness is also higher. The competition among related fungal species was low in these experiments because the fungal lineages presented functional complementarity (Maherali and Klironomos 2007), which emphasizes the importance of species conservation to preserve ecosystem functions. Loss of fungal richness in the soybean plantation and pasture areas when compared to the native Cerrado vegetation could represent the disappearance of entire fungal lineages and loss of functional complementarity. An example of a possible consequence would be a decline in plant productivity if resistance to pathogens by competition or antagonism was affected.

This is the first report of a survey of the Cerrado soil fungal community. The results presented in this study highlight the importance of the Cerrado biome and the consequences of the expansion of human activity on fungal community richness. While the flora and fauna are often the focus of studies and preservation efforts, the microbial community is neglected. Our study shows that a new view of Cerrado that takes into consideration the microbial communities should be developed. Traditional taxonomic characterization with the description of new taxa will be crucial for a better understanding and managing of the Cerrado biome and to protecting the endangered fungal species. Thus, further characterization of the fungal diversity in this threatened biome will be extremely important for the understanding of soil ecology and design of guidelines for long-term agricultural practices as well as fungal conservation. 
Acknowledgments This work was supported by CNPq, FAP/DF, UCB and Ouro Fino Veterinária grants. B.F.Q. is supported by $\mathrm{CNPq}$ grant number 472813/2006-4.

\section{References}

Altschul SF, Gish W, Miller W, Myers EW, Lipman DJ (1990) Basic local alignment search tool. J Mol Biol 215:403-410

Anderson IC, Cairney JW (2004) Diversity and ecology of soil fungal communities: increased understanding through the application of molecular techniques. Environ Microbiol 6:769-779

Anderson IC, Campbell CD, Prosser JI (2003) Potential bias of fungal 18S rDNA and internal transcribed spacer polymerase chain reaction primers for estimating fungal biodiversity in soil. Environ Microbiol 5:36-47

Arnold AE et al (2003) Fungal endophytes limit pathogen damage in a tropical tree. Proc Natl Acad Sci USA 100:15649-15654

Crecchio C, Gelsomino Ambrosoli R, Minati JL, Ruggiero P (2004) Functional and molecular response of soil microbial communities under differing soil management practices. Soil Biology \& Biochemistry. 36:1873-1883

Dashwood EP, Fox RA, Duncan JM (1993) Effect of substrate and plant maturity on the incidence of infection of potato roots by pathogenic and nonpathogenic fungi. Mycol Res 97:733-745

Doran JW, Zeiss MR (2000) Soil health and sustainability: managing the biotic component of soil quality. Appl Soil Ecol 15:3-11

Edgar RC (2004) MUSCLE: multiple sequence alignment with high accuracy and high throughput. Nucleic Acids Res 32:1792-1797

Engelen B, Meinken K, von Wintzingerode F, Heuer H, Malkomes HP, Backhaus H (1998) Monitoring impact of a pesticide treatment on bacterial soil communities by metabolic and genetic fingerprinting in addition to conventional testing procedures. Appl Environ Microbiol 64:2814-2821

Franklin E, Santos EM, Albuquerque MI (2006) Diversity and distribution of oribatid mites (Acari:Oribatida) in a lowland rain forest in Peru and in several environments of the Brazilians states of Amazonas, Rondonia, Roraima and Para. Braz J Biol 66:999-1020

Giller KE, Beare MH, Lavelle P, Izac AM, Swift MJ (1997) Agricultural intensification, soil biodiversity and agroecosystem function. Appl Soil Ecol 6:3-16

Girvan MS, Bullimore J, Ball AS, Pretty JN, Osborn AM (2004) Responses of active bacterial and fungal communities in soils under winter wheat to different fertilizer and pesticide regimens. Appl Environ Microbiol 70:2692-2701

Hawksworth DL (1991) The fungal dimensioned biodiversity: magnitude, significance and conservation. Micol Res 95:641-655

Hawksworth DL, Rossman YA (1997) Where are all the undescribed fungi? Phytopathology 87:888-891

Huber T, Faulkner G, Hugenholtz P (2004) Bellerophon: a program to detect chimeric sequences in multiple sequence alignments. Bioinformatics 20:2317-2319

Hughes JB, Hellmann JJ, Ricketts TH, Bohannan BJ (2001) Counting the uncountable: statistical approaches to estimating microbial diversity. Appl Environ Microbiol 67:4399-4406

Hunt J, Boddy L, Randerson PF, Rogers HJ (2004) An evaluation of $18 \mathrm{~S}$ rDNA approaches for the study of fungal diversity in grassland soils. Microb Ecol 47:385-395

Jizheng H, Zhihong X, Jane H (2005) Analyses of soil fungal communities in adjacent natural forest and hoop pine plantation ecosystems of subtropical Australia using molecular approaches based on 18S rRNA genes. FEMS Microbiol Lett 247:91-100

Josen K, Jacobsen CS, Torsvik V (2001) Pesticide effects on bacterial diversity in agricultural soils-a review. Biol Fertil Soils $33: 443-453$
Jumppoonem A, Trappe JM (1998) Dark-septate root endophytes: a review with special reference to facultative biotrophic symbiosis. New Phytol 140:295-310

Kirk JL et al (2004) Methods of studying soil microbial diversity. J Microbiol Methods 58:169-188

Maherali H, Klironomos JN (2007) Influence of phylogeny on fungal community assembly and ecosystem functioning. Science 316:1746-1748

Maniatis T, Fritsch EF, Sambrook J (1982) Molecular cloning: a laboratory manual. Cold Spring Harbor Laboratory Press, Plainview, NY

Marris E (2005) The forgotten ecosystem. Nature 437:944-945

Massicotte HB, Melville LH, Tackaberry LE, Peterson RL (2007) Pityopus californicus: strutural characteristics of seed and seedling development in a myco-heterotrophic species. Mycorrhiza 17:647-653

O’Donnell AG, Goodfellow M, Hawksworth DL (1994) Theoretical practical aspects of the quantification of biodiversity among microorganism. Philos Trans R Soc London B Biol Sci 345:65-73

Ohtonen R, Aikio S, Väre H (1997) Ecological Theories in Soil Biology. Soil Biol Biochem 29:1613-1619

Pappas GJ Jr, Benabdellah K, Zingales B, Gonzalez A (2005) Expressed sequence tags from the plant trypanosomatid Phytomonas serpens. Mol Biochem Parasitol 142:149-157

Powell JR et al (2007) Mycorrhizal and rhizobial colonization of genetically modified and conventional soybeans. Appl Environ Microbiol 73:4365-4367

Quirino BF et al (2007) Molecular phylogenetic diversity of bacteria associated with soil of the savanna-like Cerrado vegetation. Microbiol Res (in press)

Ratter JA, Ribeiro JF, BridGeWater S (1997) The Brazilian cerrado vegetation and threats to its biodiversity. Ann Bot 80:223-230

Reiners WA, Bouwman AF, Keller M (1994) Tropical rain forest conversion to pasture: changes in vegetation and soil properties. Ecol Appl 4:363-377

Saldarriaga Y, Pineda F, Garcia G, Velasquez LF (1994) New species of Psilocybe from Colombia and discussion of the known species. Mycotaxon 51:225-235

Schiller CT, Sinclair JB (1984) Microorganisms associated with soybean vascular exudate and plant parts. Int J Tropical Plant Dis 2:1-4

Schloss PD, Handelsman J (2004) Status of the microbial census. Microbiol Mol Biol Rev 68:686-691

Schloss PD, Handelsman J (2005) Introducing DOTUR, a computer program for defining operational taxonomic units and estimating species richness. Appl Environ Microbiol 71:1501-1506

Schloss PD, Larget BR, Handelsman J (2004) Integration of microbial ecology and statistics: a test to compare gene libraries. Appl Environ Microbiol 70:5485-5492

Schwarzenbach K, Enkerli J, Widmer F (2007) Objective criteria to assess representativity of soil fungal community profiles. J Microbiol Methods 68:358-366

Sequerra J, Marmeisse R, Valla G, Normand P, Capellano A, Moiroud A (1997) Taxonomic position and intraspecific variability of the nodule forming Penicillium nodositatum inferred from RFLP analysis of the ribosomal intergenic spacer and random amplified polymorphic DNA. Mycol Res 101:465-472

Singleton DR, Furlong MA, Rathbun SL, Whitman WB (2001) Quantitative comparisons of $16 \mathrm{~S}$ rRNA gene sequence libraries from environmental samples. Appl Environ Microbiol 67:4374-4376

Smit E, Leeflang P, Glandorf B, van Elsas JD, Wernars K (1999) Analysis of fungal diversity in the wheat rhizosphere by sequencing of cloned PCR-amplified genes encoding 18S rRNA and temperature gradient gel electrophoresis. Appl Environ Microbiol 65:2614-2621

Sutton JC, Li DW, Peng G, Yu H, Zhang P, Valdebenito-Sanhueza RM (1997) Gliocladium roseum-a versatile adversary of Botrytis cinerea in Crops. Plant Dis 81:316-328 
Swart L, Crous PW, Kang jC, Machau GRA, Pascoe I, Palm ME (2001) Differentiation of species of Elsinoe associated with scab disease of Proteaceae based on morphology, symptomology, and ITS sequence phylogeny. Mycologia 93:366-379

Theron DJ, Holtz G (1991) Dry rot of potatoes cause by Glicocladium roseum. Plant Pathol 40:302-305

Tilman D (1999) Global environmental impacts of agricultural expansion: the need for sustainable and efficient practices. Proc Natl Acad Sci USA 96:5995-6000

Udagawa S, Uchiyama S (2001) Taxonomic studies on new or critical fungi of non-pathogenic Onygenales 4. Mycoscience 42:281-287

Vandenkoornhuyse P, Baldauf SL, Leyval C, Straczek J, Young JP (2002) Extensive fungal diversity in plant roots. Science 295:2051
Wertz S et al (2006) Maintenance of soil functioning following erosion of microbial diversity. Environ Microbiol 8:2162-2169

Wertz S et al (2007) Decline of soil microbial diversity does not influence the resistance and resilience of key soil microbial functional groups following a model disturbance. Environ Microbiol 9:2211-2219

Wolfe BE, Mummey DL, Rillig MC, Klironomos JN (2007) Smallscale spatial heterogeneity of arbuscular mycorrhizal fungal abundance and community composition in a wetland plant community. Mycorrhiza 17:175-183

Yeates C, Gillings MR, Davison AD, Altavilla N, Veal DA (1998) Methods for microbial DNA extraction from soil for PCR amplification. Biol Proced Online 1:40-47 